\title{
Por la aceptación de los pactos sucesorios de institución y renuncia
}

\author{
Joel González Castillo*
}

\begin{abstract}
RESUMEN
Como es sabido, la sucesión contractual o convencional no es aceptada en nuestra legislación; sin embargo, la aceptación o rechazo de los pactos sobre sucesión futura o de algunos de ellos, es materia que suscita amplia controversia en la doctrina. Este artículo tiene por objeto analizar dichos pactos, cuestión necesariamente vinculada a la libertad de testar y a la conveniencia o no, de mantener las asignaciones forzosas. Para tal efecto, se estudia primero la tipología de dichos pactos (de institución, de disposición y de renuncia) y sus requisitos comunes, luego se exponen las razones por las que dicha distinción es plausible en el derecho nacional y se desarrollan argumentos generales y particulares para sostener la admisibilidad en nuestro ordenamiento jurídico de los pactos de institución y renuncia, debiendo quedar restringida la probibición general del artículo 1463 del Código Civil a los pactos de disposición.
\end{abstract}

Pactos sobre sucesión futura; objeto ilícito; libertad de testar

\section{In favor of the acceptance of the inheritance pacts of institution and renunciation}

\begin{abstract}
As is known, contractual or conventional inheritance is not accepted in our legislation, however, the acceptance or rejection of pacts on future inheritance or some of them is a matter that raises wide controversy in the legal doctrine. The purpose of this article is to analyze said pacts, an issue necessarily linked to the freedom to dispose of assets by will and the convenience or not of maintaining compulsory assignments. For this purpose, the typology of said agreements - of institution, disposition and renunciation - and their common requirements are studied first; then the reasons why this distinction is admissible in national law are exposed and general and particular arguments are developed to maintain the admissibility in our legal system of the pacts of institution and resignation, the general probibition of article 1463 of the Civil Code should remain restricted to the disposition pacts.
\end{abstract}

Contracts on future inheritance; illicit object; freedom to make a will

* Magíster en Derecho de la Unión Europea, Universidad Complutense de Madrid. Magíster en Derecho de la Empresa, Pontificia Universidad Católica de Chile. Profesor de Derecho Civil, Pontificia Universidad Católica de Chile. ORCID: https://orcid.org/0000-0002-4006-2631. Correo electrónico: jagonzac@uc.cl Artículo recibido el 27.2.20 y aceptado para su publicación el 15.6.20. 


\section{INTRODUCCIÓN}

$\mathrm{L}$ os países que han abordado las reformas a su Derecho de Familia, emprenden luego o conjuntamente, la tarea de revisar el estado de su Derecho Sucesorio ${ }^{1}$ y una de las cuestiones más debatidas entonces, es la libertad de testar y la aceptación, o no, de los pactos sobre sucesión futura. De ahí nuestro interés por abordar estos temas.

En nuestro país solo hay dos formas de suceder a una persona: en virtud del testamento o de la ley. Nuestro legislador no acepta la sucesión contractual; esto es, que se suceda a una persona en virtud de una convención celebrada con ella o sus herederos, antes de su fallecimiento. Son los llamados pactos sobre sucesión futura.

Nuestro Código Civil sigue el tradicional criterio romanista, consagrando con carácter general el principio prohibitivo de la sucesión contractual ${ }^{2}$. Así resulta ante todo del artículo 952, conforme con esto se limitan los modos de deferirse la sucesión al testamento y a la ley y se excluye la forma contractual.

Para Ripert y Boulanger constituye un pacto sobre sucesión futura "todo convenio efectuado en consideración de una sucesión no abierta todavía y por el cual una de las partes se hace atribuir o abdica derechos puramente eventuales en esa sucesión"3.

Guzmán Brito dice que "sucesión convencional" es aquella que tiene lugar en virtud de un acuerdo entre el (futuro) causante y un tercero, tenga o no previo título para suceder, o viviendo el (futuro) causante, entre los que esperan suceder, tengan o no dicho título. Tradicionalmente, se llama "pactos sucesorios" a tales acuerdos. Estos pactos pueden tener diversas causas como compraventa, permuta o donación. Así, el futuro heredero podría vender o donar la herencia que espera conseguir de alguien que ahora vive, a un tercero; y entonces, se trata en realidad de una compraventa o de una donación. Pese a todo, se habla de pactos sin más ${ }^{4}$.

Por su parte, Diez-Picazo y Gullón llaman "contrato sucesorio" a todo negocio jurídico bilateral que produce sus consecuencias respecto de la herencia de la persona. Paralelamente, hay sucesión contractual cuando la ordenación del fenómeno hereditario se produce total o parcialmente por medio de un contrato. El contrato sucesorio, continúan los autores españoles, es, en alguna medida, un negocio jurídico de naturaleza sui generis. No es un contrato genuinamente obligacional ni tampoco un contrato con efectos reales pues no origina desplazamientos patrimoniales. Su efecto sustancial es puramente mortis causa y consiste en dejar disciplinada, de una determinada manera, vinculante para las partes, una sucesión mortis causa. El causante, en principio, no ve limitado, por contrato sucesorio, su poder de disposición entre vivos ni queda tampoco obligado a no establecer en el futuro disposiciones contradictorias con el contrato. El efecto sustancial

1 Acerca de la evolución del Derecho de Familia y del Derecho Sucesorio y su interrelación, vid. Abeliuk, 2009, pp. 55-70; Rodríguez, 1989, pp. 25-34; SAavedra, 2007, pp. 113-132.

${ }^{2}$ En palabras de Castán, fue el Derecho Romano el que "alimentó una hostilidad declarada hacia los pactos sucesorios, que habría de subsistir secularmente”. CASTÁn, 1964, p. 92.

${ }^{3}$ Ripert y Boulanger, 1965, p. 27.

${ }^{4}$ GuZMán, 2001, p. 561. 
es el establecimiento convencional de una disciplina sucesoria. Del carácter convencional deriva la eficacia vinculante de lo pactado y, en principio, su irrevocabilidad; de ahí una especial diferencia con el testamento. Además, y precisamente por ello, el contrato sucesorio podrá ser impugnado por el otorgante durante su vida, cosa que no ocurre nunca con el testamento, pues basta, en definitiva, revocarlo 5 .

En Chile, la prohibición de pactos sobre sucesiones futuras constituye un principio de carácter general que no se encuentra específicamente regulado en materia de asignaciones forzosas, sino que está incorporado en las reglas generales sobre actos y declaraciones de voluntad en el libro IV del Código Civil, especialmente a propósito del objeto como requisito del acto jurídico, y en particular, a propósito de la prohibición de ilicitud. En efecto, el artículo 1463 repudia expresamente dichos pactos. Dice el precepto en su primer inciso que el derecho de suceder por causa de muerte a una persona viva no puede ser objeto de una donación o contrato, aun cuando intervenga el consentimiento de la misma persona ${ }^{6}$.

${ }^{5}$ Díez-Picazo y Gullón, 2000, p. 513.

${ }^{6}$ Al igual que nuestro artículo 1463 el Código italiano, en su artículo 458, declara: Es nula toda convención por la que alguien dispone de la propia sucesión. Todo acto por el cual alguien dispone de los derechos que le pueden corresponder sobre una sucesión aún no abierta o renuncia a los mismos también es nulo. Como se ve el Codice proscribe los tres tipos de pactos sucesorios. Por su parte el Código Civil español en su artículo 1271, inciso $2^{\circ}$ señala: Pueden ser objeto de contrato todas las cosas que no están fuera del comercio de los hombres, aun las futuras. Sobre la herencia futura no se podrá, sin embargo, celebrar otros contratos que aquellos cuyo objeto sea practicar entre vivos la división de un caudal y otras disposiciones particionales, conforme a lo dispuesto en el artículo 1056. Esta última norma a su vez dispone: Cuando el testador hiciere, por acto entre vivos o por última voluntad, la partición de sus bienes, se pasará por ella, en cuanto no perjudique a la legítima de los herederos forzosos. El testador que en atención a la conservación de la empresa o en interés de su familia quiera preservar indivisa una explotación económica o bien mantener el control de una sociedad de capital o grupo de estas podrá usar de la facultad concedida en este artículo, disponiendo que se pague en metálico su legítima a los demás interesados. En algunas legislaciones europeas, con el objeto de aumentar la libertad de disposición o con fines netamente económicos, específicamente para mantener la unidad de establecimientos de comercio, empresas familiares o unidades agrícolas, se ha permitido el establecimiento de ciertos y determinados contratos sobre una sucesión futura. Así, en Alemania el BGB prohíbe únicamente los pactos de disposición (parágrafo 2278), y acepta los de institución y renuncia (parágrafo 2346). En Francia, con la reforma del año 2006, se establece el pacto mediante el cual un legitimario puede renunciar a la acción de reducción. El Code en su artículo 929 dispone: Cualquier presunto heredero legitimario podrá renunciar a ejercer una acción de reducción en una sucesión no abierta. Como explica Barría la reforma tiene un carácter netamente económico, pues con ello el causante puede dejar una empresa familiar o unidad económica a otro legitimario o a un tercero. Luego, si otro legitimario renuncia a la acción, entonces se consolidará el dominio de dicha empresa o unidad en el donatario beneficiado, no pudiendo el perjudicado ejercer la acción y, como consecuencia de ello, mantener íntegramente la empresa familiar o unidad económica, evitando su extinción. BARRÍA, 2018, p. 141. En todo caso es importante señalar que en Francia al igual que en Chile la regla general es el rechazo a los pactos de sucesión futura. En efecto, el art. 1130 del Código francés prescribe que Las cosas futuras pueden ser objeto de una obligación. No se puede, sin embargo, renunciar a una sucesión aún no abierta, ni hacer ninguna estipulación sobre una sucesión semejante, aun con el consentimiento de aquel de cuya sucesión se trata, sino en las condiciones previstas en la ley. El nuevo Código Civil y Comercial argentino inspirado en el Code francés dice en su artículo 1010: Herencia futura. La herencia futura no puede ser objeto de los contratos ni tampoco pueden serlo los derechos hereditarios eventuales sobre objetos particulares, excepto lo dispuesto en el párrafo siguiente u otra disposición legal expresa. Los pactos relativos a una explotación productiva o a participaciones societarias de cualquier tipo, con miras a la conservación de la unidad de la gestión empresaria o a la prevención o solución de conflictos, pueden incluir disposiciones referidas a futuros derechos hereditarios y establecer compensaciones en favor de otros legitimarios. Estos pactos son válidos, sean o no parte el futuro causante y su cónyuge, si no afectan la legítima bereditaria, los derechos 
De llegar a celebrarse tales pactos, la ley les señala como sanción la nulidad absoluta por objeto ilícito (art. 1682). Queda así prohibida la sucesión contractual o pactada, resultando vedados: (i) los pactos de institución de heredero o legatario, (ii) los pactos de renuncia y (iii) la cesión de los derechos en la sucesión de una persona que no ha fallecido.

El precepto transcrito habla de "donación o contrato", siendo que en realidad la donación no es sino una especie de contrato; lo que quiso decir el legislador es que la prohibición abarca tanto a los actos onerosos como a los gratuitos, relativos al derecho de suceder por causa de muerte a una persona que aún vive ${ }^{7}$.

Si bien el artículo 1463 establece una regla general prohibitiva de los pactos sucesorios, como ha sido señalado por la doctrina y por la jurisprudencia, la prohibición no incide en aquellos pactos y estipulaciones que no sean propiamente sucesorios aunque guarden relación con una herencia. La prohibición legal se refiere solo a los contratos concluidos sobre la herencia futura misma o sobre alguna de sus cuotas. La jurisprudencia, como desarrollaremos a lo largo de este trabajo, ha aplicado la prohibición pero limitándola a los pactos en que efectivamente se contrate, sobre el derecho de suceder a un tercero. Por eso, no basta para que se aplique la sanción, que un contrato se refiera a la sucesión futura de una persona, como si se propone una recompensa a cambio de un servicio; recompensa que tendrá efecto después de la muerte del proponente ${ }^{8}$ o si se conviene un pacto de separación de bienes sobre una herencia futura ${ }^{9}$, porque en tales casos no se ha dispuesto del derecho a suceder en sí mismo. Pero sí está afecto a nulidad absoluta el pacto en que una persona designe a otro partidor y administrador proindiviso de la herencia que vaya a corresponderle en los bienes de un tercero, agregando como

del cónyuge, ni los derechos de terceros. En su recién publicado trabajo sobre la disposición transcrita Córdoba señala que la norma en análisis entiende que frente a la protección de la familia, como objeto legal, existe otro aspecto que es necesario considerar, y es el referido al mantenimiento de los establecimientos comerciales, industriales, agrícolas, ganaderos, mineros o cualquier otro que constituya una unidad económica ante el fallecimiento de la persona que ejerce su control. Se considera que ello debe estar al servicio de la estabilidad de las relaciones jurídicas por la necesidad del tráfico. Existiendo así derechos encontrados el legislador ha optado por el interés más digno de protección, pues con él se impulsa la vida productiva que es base del progreso. Se adopta un rol dinámico y mediante la excepción a la prohibición de los pactos sucesorios se da solución estimulando la actividad económica. En la necesidad de asegurar y armonizar los derechos subjetivos, se ha intentado conciliar el orden y el movimiento (CórdoBA, 2019, p. 98), soluciones que de otro modo serían inviables, pues el testamento resulta insuficiente para su instrumentación (FERRER, 2015, p. 864). Se ha creado con ello un nuevo orden moral, ya que durante la vigencia del código derogado la doctrina autoral y jurisprudencial coincidía en que la prohibición de la ley se basaba en la inmoralidad de los tratos sobre herencias de personas vivas (ForNieles, 1941, p. 87). Sobre esto Córdoba destaca que "la inclusión de la excepción normativa que autoriza el pacto (sobre sucesión futura) implica una transformación del orden moral por cuanto se ha producido una modificación de las normas imperativas y se ha optado por la omisión de las antiguas buenas costumbres en una transformación justificada en necesidades del tráfico. Los pactos con el contenido descrito han dejado de ser contrarios a las normas imperativas y también a las buenas costumbres, es decir, ya no son de objeto ilícito" (Córdoba, 2019, p. 95).

${ }^{7}$ Vid. por todos Somarriva, 2005, p. 22; León Hurtado, 1983, p. 48.

${ }^{8}$ Corte Suprema, 31.5.1907.

${ }^{9}$ Corte Suprema, 26.4.1934. 
remuneración, un tanto por ciento de los bienes que se reciban ${ }^{10}$. Por el contrario, se ha encargado también la jurisprudencia de cautelar que la prohibición sea respetada, anulando incluso contratos de compraventa simulados que tienden exclusivamente a vulnerar el art. 1463, dando forma jurídica distinta a acuerdos que, en el fondo, involucran pacto sobre sucesión futura ${ }^{11}$.

\section{Tipología de los pactos sucesorios. Requisitos}

Los pactos sucesorios admiten distintas clasificaciones en función de qué aspecto se quiera destacar. En función del objeto, los pactos sucesorios pueden $\operatorname{ser}^{12}$ :

$1^{\circ}$ Pactos de institución, en los que una persona se compromete a dejar como heredero a otra; este pacto puede ser recíproco.

$2^{\circ}$ Pactos de renuncia, en los que una persona renuncia anticipadamente a sus posibles derechos hereditarios en la sucesión del causante.

$3^{\circ}$ Pactos de disposición, por los cuales el futuro heredero en vida del causante dispone de sus derechos en la sucesión, es decir, los enajena a un tercero.

Para que cualquiera de estos pactos califiquen como uno sobre sucesión futura, deben reunir tres requisitos: a) el pacto debe celebrarse en vida del causante, es decir, antes de la apertura de la sucesión, b) el pacto debe versar sobre la totalidad, o sobre una parte alícuota de la sucesión futura o sobre bienes o derechos comprendidos en ella y c) el promitente debe tener un derecho puramente sucesorio, sobre el objeto del pacto ${ }^{13}$.

\section{${ }^{10}$ Corte Suprema, 5.1.1954}

${ }^{11}$ Corte de Apelaciones de Santiago, 29.11.1960. El razonamiento de esta sentencia fue: "Si en el periodo en que se celebraron los contratos impugnados de nulidad, la demandada hacía vida marital con el padre de la demandante, figurando este como vendedor y aquella como compradora en dos de ellos y como cedente de sus derechos a la misma en el otro, y queda establecido que al comienzo de las relaciones extraconyugales la demandada recién abandonaba su cargo de garzona en una fuente de soda, sin que haya aportado antecedente alguno que demuestre o haga presumir un indicio siquiera de recursos económicos anteriores; que a la fecha de dichos contratos el vendedor y cedente se encontraba gravemente enfermo, falleciendo poco más de un mes después de celebrar el primero y a pocos días del último, sin que se divise en autos alguna necesidad imperiosa o ineludible que lo obligara o aconsejara a desprenderse de todos sus bienes, sin excepción, en circunstancias de que en un testamento otorgado un mes antes de celebrar el primer contrato dejaba todos sus bienes a la demandante (su hija legítima), y que solo revocó estas disposiciones por otro testamento otorgado el mismo día en que celebró el último, cabe desprender un sinnúmero de presunciones graves, precisas y concordantes, suficientes, a juicio del tribunal, para formar el convencimiento legal de que en los tres contratos aludidos no solo se falseó la naturaleza, sino que no hubo entre las partes contratantes el consentimiento real y efectivo para pactar las prestaciones que mutuamente se imponen, ni motivo lícito determinante para celebrarlos, y que se trata de contratos simulados tendientes a burlar la prohibición de pactar sobre el derecho a suceder establecida en el artículo 1463 del Código Civil”.

${ }^{12}$ Ver las distintas clasificaciones de pactos sucesorios en RODRíGUEZ-URía, 2013, pp. 26-29.

${ }^{13}$ Vid. por todos Claro Solar, 1992, p. 284. 
En cuanto al primer requisito, si el pacto se celebra antes de la apertura, no habrá dificultades para declarar su nulidad. Pero puede suceder que las partes contraten de buena fe, creyendo erradamente que la persona de cuya sucesión se trata ha fallecido, o, por la inversa, creyendo que esa persona está viva, en circunstancias que ha fallecido con anterioridad a la convención. La solución de ambos casos se obtiene prescindiendo de la intención de los contratantes; o sea, en el primer supuesto el pacto es nulo (además, si las partes de buena fe, creen contratar sobre una sucesión abierta, que en realidad no lo está, el objeto no existe. Y si saben que no está abierta, hay objeto futuro pero ilícito. Y en ambos supuestos, existe nulidad absoluta) y en el segundo, es válido. La sola intención de celebrar un acto válido no sanea los vicios que contenga y la simple creencia de las partes de ejecutar un acto prohibido por la ley, no puede hacer ilícito el acto que se realice si no está prohibido ${ }^{14}$.

Luego, el pacto debe versar sobre la totalidad o una parte alícuota de la sucesión o sobre bienes o derechos comprendidos en ella pero, pactándose claramente sobre esos bienes o derechos. Por eso, nuestra Corte Suprema en el caso de una señora que pidió a una sobrina suya que se trasladara desde Santiago a París para cuidarla, prometiéndole "recompensar su sacrificio y asegurarle su porvenir con una gran parte de su fortuna", y agregando, además, "tú ves que no tengo herederos”, resolvió que tal estipulación no constituye un pacto sobre sucesión futura. Dijo nuestro más alto tribunal "que de la lectura de este documento -carta en que proponía el contrato- resulta asimismo, que el contrato no versó de ninguna manera sobre una sucesión no abierta; porque si bien en su texto expuso la señora Real de Azúa que carecía de herederos, lo hizo indudablemente, no para que el todo o parte de su herencia sirviera de objeto o materia de la convención, sino para indicar de un modo insinuante o la magnitud de la recompensa prometida por los 'sacrificios' que solicitaba de la señorita Mandiola o posiblemente, para dar a entender que dichos sacrificios podrían ser pagados, no solo en cualquier forma legal, sino también en la de una asignación testamentaria; pero en todo caso, aparece de resalto que el derecho de la señorita Mandiola a la 'recompensa prometida' no quedó subordinado a una asignación de esta naturaleza y, por consiguiente, el pacto que acusa la carta no adolece de objeto ilícito, como se pretende" 15 . León Hurtado comenta que la Corte Suprema resuelve acertadamente el caso, pues la remuneración se promete hacerla "con gran parte de la fortuna” y esto pudo hacerlo la oferente en vida o sus herederos después de muerta. La referencia a que ella carecía de herederos, no puede mirarse sino como una insinuación de la magnitud de la recompensa, en cuanto no había quién pudiera discutir u oponerse a la suma que se fijara. Además, con ello se podía dar a entender que el pago podría hacerse con una asignación testamentaria pero esa recompensa no quedó subordinada a una asignación de esta naturaleza y, en consecuencia, no se estipuló sobre

\footnotetext{
${ }^{14}$ Cfr. León Hurtado, 1983 , p. 51.

${ }^{15}$ Corte Suprema, 31.5.1907.
} 
una sucesión futura específicamente, como exige el art. 1463 para que se produzca la ilicitud del objeto ${ }^{16}$.

Finalmente, para que opere la prohibición legal, debe tratarse de una estipulación que se refiera al derecho de suceder por causa de muerte. Nuestra Corte Suprema ha fallado, aplicando este criterio, que "no se infringe el art. 1463 al aceptar como válido el pacto de separación de bienes sobre una herencia futura, pues no hay en él un contrato sobre el derecho a suceder por causa de muerte a una persona viva, que es lo que dicho artículo prohíbe" 17 .

Las razones que han motivado la prohibición de los pactos sobre sucesión futura pueden sintetizarse así: (i) son inmorales porque en ellos se especula con la muerte de una persona, (ii) peligrosos dado que pueden impulsar al interesado a atentar contra la vida del causante ${ }^{18}$, (iii) la prohibición tiene por objeto la protección e igualdad de los legitimarios ${ }^{19}$; pues de no existir, el causante podría celebrar contratos con otros legitimarios o con terceros, para perjudicar sus derechos hereditarios futuros ${ }^{20}$, (iv) la prohibición de los pactos de sucesión futura busca la protección de quienes, teniendo expectativas de heredar en un porvenir, que estiman lejano, impulsados por la necesidad o la ambición o con ligereza y, por tratarse de un derecho incierto, estarían dispuestos a enajenar por un precio insignificante sus eventuales derechos a una sucesión futura, mediante contratos casi siempre lesivos y (v) estos pactos atentarían contra la libertad de testar ya que el futuro causante no puede desligarse de su compromiso por su sola voluntad y tendría que cumplir esta obligación de origen contractual ${ }^{21}$.

${ }^{16}$ LeÓn Hurtado, 1983, p. 52.

${ }^{17}$ Corte Suprema, 26.4.1934. Esta sentencia tiene su fundamento en el texto originario del artículo 1715 que disponía: "Se conocen con el nombre de capitulaciones matrimoniales las convenciones que celebran los esposos antes de contraer matrimonio, relativas a los bienes que aportan a él, y a las donaciones y concesiones que se quieran hacer el uno al otro, de presente o futuro" (énfasis agregado). La Corte resolvió que entre las concesiones de futuro autorizadas por el artículo 1715, para que se hagan los esposos en las capitulaciones matrimoniales, bien puede figurar la de reservar para la mujer, la administración de bienes futuros como los de una herencia futura. En la especie, se había acordado esto último entre los esposos, y la Corte Suprema acertadamente falló que no había vulneración del artículo 1463, por cuanto el objeto de tal pacto no era el derecho a suceder por causa de muerte a una persona viva, que es lo prohibido, sino solo que la mujer administrara esos bienes.

${ }^{18}$ Vid. por todos Somarriva, 2005, p. 23; León Hurtado, 1983, pp. 48-49.

${ }^{19}$ Sobre la igualdad en materia sucesoria véase PeÑalliLlo, 1968, pp. 59-109.

${ }^{20}$ Vid. por todos BARría, 2018, p. 151. El Código Civil francés, heredero de la Revolución, prohibió los pactos sucesorios porque eran una amenaza a la igualdad que debía imperar entre los hijos en la repartición de las herencias. Hay que recordar que una de las formas tradicionales de disposición mortis causa en Francia, había sido el pacto sucesorio utilizado para favorecer la transmisión indivisa del patrimonio familiar a uno solo de los descendientes, el primogénito. La revolución advirtió que una forma efectiva de terminar con la aristocracia y las grandes fortunas del antiguo régimen, consistía en impedir la libertad de testar e impuso la división igualitaria de la herencia entre los hijos. Así lo explica DoyHarcabal, 2008, pp. 23-26.

${ }^{21}$ Así lo sostienen Ripert y Boulanger: "Finalmente está la idea, ya sacada a luz por los jurisconsultos romanos, de que el pacto sobre la sucesión futura es contrario a la libertad de testar; limita o aun suprime completamente esa libertad. El contrato crea una situación definitiva; el que ha sido instituido heredero está seguro de conservar esa condición; el que ha renunciado se ha condenado a ser ajeno a la sucesión. Pero uno 
En cuanto a que los pactos serían peligrosos e inmorales, estos argumentos, en realidad, no son muy decisivos porque hoy son muchos los contratos e instituciones jurídicas en que está en juego la vida de una persona y, sin embargo, el legislador los acepta expresamente. Tal cosa ocurre en el usufructo, la renta vitalicia, el seguro de vida, el seguro de desgravamen, etcétera. Con razón, se ha dicho que "tal vez sea de una psicología un tanto rudimentaria pretender que el pacto es inmoral porque incita a formular el votum mortis captandae. Eso no es exacto, además, para todos los pactos, particularmente para las renuncias" 22 ; no se puede atribuir a los pactos de renuncia a una herencia futura, la connotación de peligrosos porque el renunciante carece de interés en anticipar el fallecimiento del futuro causante.

Asimismo, los argumentos para justificar la prohibición, basados en la pérdida de la absoluta libertad de disponer mortis causa que debe reconocerse a toda persona, tampoco nos parece convincente, pues en realidad no puede hablarse de una absoluta libertad para disponer mortis causa, cuando esta libertad ya está reducida en buena medida por normas de carácter imperativo (asignaciones forzosas), sin olvidar, por otra parte, que el contrato sucesorio, como todo contrato, es un acto de ejercicio de la libertad y del poder de autonomía y que si al otorgar el contrato, la libertad se pierde, es precisamente porque se ha ejercitado. Además, este argumento - pérdida de la libertad de testar-solo es aplicable a los pactos de institución pero no aplica a los de renuncia o disposición.

En relación con los argumentos para rechazar los pactos de sucesión, nuestra jurisprudencia ha dicho que para fijar el alcance del artículo 1463, conviene recordar que, al consignarlo, el legislador refundió en un solo texto diversas disposiciones del Código de Napoleón que, con algunas excepciones que, en general, no caben entre nosotros, prohíben sustancialmente: renunciar a una herencia futura, celebrar contratos en que una persona estipule sobre su propia sucesión y efectuar actos de disposición o de administración, sobre los derechos eventuales que se tienen sobre una sucesión aún no abierta. Por lo demás, solo esos pactos pueden contrariar las razones que se han tenido en vista para prohibirlos, o sea, las de evitar que se especule sobre la vida de una persona, que se alteren las reglas de la sucesión o se viole la libertad de testar y que aún se pueda llegar a atentar contra la vida del causante ${ }^{23}$.

de los principios fundamentales de nuestro derecho sucesorio es que, hasta el último momento, una persona puede revocar las disposiciones que haya adoptado con respecto a la transmisión de su sucesión. La revocabilidad del testamento es incompatible con la irrevocabilidad del contrato. Este argumento no afecta evidentemente a los pactos relativos a la sucesión de un tercero; pero conserva todo su valor, que es considerable, con respecto a todos los demás". Ripert y Boulanger, 1965, pp. 26, 27, 32. En el mismo sentido Messineo dice que: "La prohibición del pacto institutivo es el resultado del principio de la libertad de disponer, o sea, de la revocabilidad del testamento hasta el momento de la muerte; el cual quedaría vulnerado por el vínculo obligatorio que derivaría al testador del pacto sucesorio: vínculo que sería inmodificable, por parte del disponente, si el otro contratante, destinatario de los bienes (heredero o legatario), no consintiese en la modificación; y así, por vía transversal, quitaría al testamento el carácter de revocabilidad”. MessineO, 1979, p. 75.

22 Ripert y Boulanger, 1965, p. 25.

${ }^{23}$ Corte de Apelaciones de Valparaíso, 29.4.1933. 


\section{Admisiblidad de la distinción de los PACTOS SUCESORIOS EN EL DERECHO NACIONAL}

Es admisible preguntarse si la tripartita distinción de los pactos sobre sucesión futura (de institución, renuncia y disposición) es plausible en el derecho nacional. La respuesta, creemos, es afirmativa. Por de pronto, la doctrina está conteste que el artículo 1463 comprende las diversas clases de pactos, impidiendo "la renuncia a suceder a una persona viva, o el pacto de institución de heredero o legatario o la cesión onerosa o gratuita del derecho a suceder al futuro causante [pacto de disposición]. La norma del artículo 1463 es amplia, no solo impide la institución de heredero por contrato, sino que también impide la intervención de terceros en una sucesión futura, prohibiéndose, incluso, la aceptación de una herencia o legado antes de ser deferidos (artículo 1226)"24.

Por otra parte, de diversas disposiciones, se puede concluir que nuestro Código, aunque sea para rechazarlos, admite, sin nombrarlos, esta distinción entre los pactos sucesorios.

En efecto, los pactos de institución pueden desprenderse del inciso $2^{\circ}$ del artículo 1463 y del inciso $2^{\circ}$ del artículo $1204^{25}$. La primera de dichas normas dice: Las convenciones entre la persona que debe una legítima y el legitimario, relativas a la misma legítima o a mejoras, están sujetas a las reglas especiales contenidas en el título "De las asignaciones forzosas"26; por su parte el inciso $2^{\circ}$ del artículo 1204 dispone: Cualesquiera otras estipulaciones sobre la sucesión futura, entre un legitimario y el que le debe la legítima, serán nulas y de ningún valor. El inciso $1^{\circ}$ de esta última norma, contempla el único caso de pacto sucesorio admitido en nuestra legislación, y es precisamente, uno de institución. Su texto es: Si el difunto bubiere prometido por escritura pública entre vivos a su cónyuge o a alguno de sus descendientes o

${ }^{24}$ Elorriaga, 2010, p. 9. En igual sentido, Claro Solar, 1992, pp. 277-278.

${ }^{25}$ La Corte Suprema, confirmando lo resuelto por la Corte de Apelaciones de Talca, anuló un convenio por estimar que contenía un pacto de institución de heredero, atendido que: "El convenio a virtud del cual el adjudicatario se obliga a no enajenar ni gravar con derecho real los bienes raíces que se le adjudican y a dejarlos pasar después de sus días a sus hijos o herederos legítimos designados en el testamento de su cónyuge, acuerdo que, aprobado por todos los herederos, se ordenó inscribirlo en el Conservador de Bienes Raíces, no importa la constitución de un usufructo. En dicho caso el adjudicatario adquiere el dominio exclusivo y absoluto, aunque comprometiéndose a dejarlos al fallecimiento a los hijos de su cónyuge, que eran también suyos. Dicha estipulación no tiene en realidad otro aspecto ni es en efecto otra cosa que un contrato relativo al derecho de suceder por causa de muerte al adjudicatario, mediante el cual éste dispone de los bienes adjudicados para después de sus días sin el derecho de revocar esta disposición a su voluntad, o mejor dicho, en virtud de la cual renuncia a su facultad de testar con respecto a los mencionados bienes. Semejante estipulación, que tan sustancialmente destruye las disposiciones legales relativas a la testamentifacción, infringiendo al propio tiempo la terminante y explícita prohibición del art. 1463 del Código Civil, es no solamente anulable, sino inexistente y radicalmente nula. El derecho que corresponde al cónyuge sobre las gananciales en la sociedad conyugal se los asigna la ley, por derecho propio, a título de dominio y sin limitación alguna." (Corte Suprema, 20.8.1928).

${ }^{26}$ Como observa Elorriaga, el inciso $2^{\circ}$ del artículo 1463 , incurre en una impropiedad, cuando sugiere que pueden existir convenciones entre la persona que debe una legítima y el legitimario. Ello no es posible pues lo único que se permite es la convención que consista en no disponer de la cuarta de mejoras. Elorriaga, 2010, p. 432. 
ascendientes, que a la sazón era legitimario, no donar, ni asignar por testamento parte alguna de la cuarta de mejoras, y después contraviniere a su promesa, el favorecido con esta tendrá derecho a que los asignatarios de esa cuarta le enteren lo que le habría valido el cumplimiento de la promesa, a prorrata de lo que su infracción les aprovechare. En verdad, dice León Hurtado, este pacto solemne que permite la ley está redactado en forma negativa porque, en el fondo, importa la renuncia a la facultad de dejar la cuarta de mejoras "a su cónyuge o a uno o más de sus descendientes o ascendientes, sean o no legitimarios" (art. 1184) y "la renuncia de esta facultad viene a significar un pacto de institución porque el heredero adquiere por una convención, derechos en esa cuarta de la cual el causante habría podido disponer en favor de las personas indicadas con entera libertad a no mediar tal convención" 27.

En lo relativo a los pactos de renuncia, ellos se infieren del inciso final del artículo 1226 que dispone: se mirará como repudiación intempestiva, y no tendrá valor alguno, el permiso concedido por un legitimario al que le debe la legítima para que pueda testar sin consideración a ella. Esta norma no hace sino aplicar la regla general del artículo 1463, que prohíbe los pactos sobre sucesión futura. La autorización dada por el legitimario al testador, para que este pueda testar sin considerar su legítima es un pacto sobre el derecho de suceder a una persona y, en consecuencia, adolece de objeto ilícito y su sanción es la nulidad absoluta. El precepto condena la renuncia anticipada, de las legítimas porque, siendo esta una asignación forzosa (art. $1167 \mathrm{~N}^{\circ}$ 2), debe ser respetada en todo momento por el testador ${ }^{28}$.

Finalmente, en cuanto a los pactos de disposición, por los cuales el futuro heredero en vida del causante, dispone de sus derechos en la sucesión, es decir, los enajena a un tercero, es cuestión no controvertida, que quedan comprendidos en los amplios términos del artículo 1463 inciso $1^{\circ}$. La doctrina, como se explicó supra, y nuestros tribunales lo han entendido siempre así2 ${ }^{29}$.

${ }^{27}$ LeÓn Hurtado, 1983, pp. 55-56.

${ }^{28}$ León Hurtado sostiene que la declaración unilateral produce igual efecto que un pacto de renuncia. Si en lugar de un pacto de renuncia, el interesado hace una declaración unilateral de voluntad, se aplican los mismos principios. León Hurtado, 1983, p. 53. Díez-Picazo y Gullón señalan que el pacto de renuncia se diferencia de la repudiación de la herencia, en que esta es siempre unilateral y recae sobre una sucesión ya abierta, mientras que el pacto renunciativo nace de un acuerdo bilateral y se produce antes de la apertura de la sucesión. Díez-Picazo y Gullón, 2000, p. 514. La jurisprudencia nacional ha resuelto, en cuanto a la renuncia a la herencia de una persona viva que: "Es nula toda renuncia de una asignación antes de la delación de la herencia. Tiene objeto ilícito la renuncia de un hijo de lo que podría tocarle en una sucesión, a cambio de una suma de dinero que le hace el padre. Aceptar la validez de esa renuncia sería autorizar una manera de gravar o menoscabar las legítimas o un nuevo modo de desheredación no establecido expresamente por las leyes. También es nula la renuncia ya se considere como pacto sobre la sucesión de una persona viva o ya como gravamen o menoscabo de la legítima, según los artículos 1204 y 1463 del Código Civil”. Corte de Apelaciones de Concepción, 25.8.1863, Gaceta de los Tribunales, 1863, No 1.984, p. 753.

${ }^{29}$ En este sentido, Corte de Apelaciones de Valparaíso, 29.4.1933. La Corte Suprema vio un pacto de esta naturaleza en el siguiente caso: "El pacto que emana del documento en que una persona expresa que en caso de llegar a ser heredera abintestato de un tío suyo se obliga desde luego a nombrar a un individuo partidor de la herencia y administrador proindiviso de los bienes que la formen, agregando que, como remuneración por el desempeño de estos cargos y de todos los servicios que este prestó en vida de su tío, le asigna desde ya y se compromete a pagarle un honorario equivalente a un $50 \%$ de lo que ella herede, se halla comprendido 


\section{RAZONES A FAVOR DE LOS PACTOS DE INSTITUCIÓN Y RENUNCIA}

El tema que desarrollamos, tiene estrecha relación con uno mayor; la libertad de disposición (término más amplio que la libertad de testar, pues comprende además de esta, la posibilidad de pactos sucesorios) y a su vez, con la gran limitación que dicha libertad tiene en nuestro país, las asignaciones forzosas ${ }^{30}$. En efecto, una de las manifestaciones de la libertad de disposición, entre otras, es permitir los pactos sobre sucesión futura, otra es la eliminación de límites a esa libertad como lo son las asignaciones forzosas.

Consideraciones o razones de orden más general y otras particulares para cada uno de los dos pactos referidos, nos llevan a postular o sostener su admisibilidad en nuestra legislación. La aceptación de una amplia libertad de disposición, y el rechazo a las asignaciones forzosas ${ }^{31}$, figuran entre las primeras razones.

En un reciente trabajo, Elorriaga ha hecho una síntesis de las razones que se dan para ampliar la libertad de $\operatorname{testar}^{32}$ (aplicables en todo, a la libertad de disposición por la que abogamos): la protección constitucional del derecho de propiedad (en especial, se afectaría la facultad de disposición); los legitimarios y asignatarios de mejoras, no tienen una especie de dominio sobre el patrimonio del causante; no es razonable pensar que la ley puede hacer mejor distribución de los bienes que el testador; en la actualidad no parecería suficiente para justificar la institución de las asignaciones forzosas, la permanencia post mortem de la obligación de los padres de alimentar a los hijos; la expansión de la seguridad social; la libertad de testar es lo que mejor se aviene con una deseable autoridad paterna; el aliciente para el emprendimiento; la fragmentación de la propiedad familiar no se condice con la moderna realidad socioeconómica; la reforma de la concepción de la realidad familiar desde la década del setenta; la escasa libertad de

dentro de los casos que contempla el artículo 1463 del Código Civil, y afecto, por lo tanto, a la prohibición que en él se establece y que lo hace adolecer del vicio de nulidad absoluta, toda vez que recayó sobre un objeto ilícito, prohibido por la ley". Corte Suprema, 5.1.1954. En este fallo, la Corte Suprema enmienda las sentencias de primera y de segunda instancia y fija, dice León Hurtado, la buena doctrina pues el pacto referido versó sobre la cesión del cincuenta por ciento de los bienes de una sucesión no abierta, cesión que hizo la presunta heredera a un tercero. León HuRTAdo, 1983, p. 57.

${ }^{30}$ Sobre la tensión entre libertad de testar y asignaciones forzosas, véase ELORRIAGA, 2019, pp. 67-102; Grimaldi, 2015, pp. 191-215; Rodríguez Pinto, 2010, pp. 423-433; Martinic, 2005, pp. $479-486$.

${ }^{31}$ Es conocida la opinión de Bello, contraria a las legítimas: "Las legítimas no fueron conocidas en Roma, mientras a la sombra de las virtudes republicanas se mantuvieron puras las costumbres y severa la disciplina doméstica. Las legítimas no son conocidas en la mayor parte de la Gran Bretaña y de los Estados Unidos de América (...). Cuanto más suave el yugo de las leyes, más poderosa es menester que sea la venerable judicatura que la naturaleza confiere a los padres (...). El establecimiento de legítimas no solo es vicioso porque es innecesario (pues no deben multiplicarse las leyes sin necesidad), sino porque, complicando las particiones, suscitando rencillas y pleitos en el seno de las familias, retardando el goce de los bienes hereditarios, ocasiona a los herederos un daño muy superior al beneficio que pudiera una vez acarrearles”. Nota de Bello al art. 1343 N4 del Proyecto de Código Civil de 1853 (correspondiente al actual art.1182). Bello, 1888, p. 316.

32 "La libertad de testar es la prerrogativa, facultad o derecho subjetivo que el ordenamiento jurídico reconoce a una persona viva para que pueda disponer a través de un testamento y en la forma que desee, de todos sus bienes, derechos y obligaciones transmisibles, para que esta disposición patrimonial tenga completo efecto después de su muerte". Elorriaga, 2019, p. 67. 
testar induce a actos encubiertos o fraudulentos y la existencia de asignaciones forzosas generan problemas habituales de difícil solución ${ }^{33}$.

Compartimos opiniones, en el sentido de que una vez que los hijos han finalizado su formación, los padres y los hijos no deben tener obligaciones legales entre sí, ni siquiera las de carácter sucesorio. Solo deben obligarse o disponer voluntariamente, de lo que el afecto les dicte. La Constitución es ampliamente permisiva, para todas las personas, también para los padres, y esto se olvida con mucha facilidad. Una vez que han sido liberados de las obligaciones y responsabilidades, para con sus hijos (en nuestro país, en especial por haber cumplido el mandato constitucional del deber de educación del art. 19 No 10 de la Constitución Política), los padres deben gozar de plena libertad de testar. Quien ya ha hecho lo que debe, no puede o, al menos, no debería quedar obligado a más ${ }^{34}$.

Por otra parte, los fundamentos sobre los cuales descansa la imposición de asignaciones forzosas en Chile, han desaparecido. El cuadro de una viuda rodeada de menores, que es una visión muy propia de la época en que se dictó nuestro Código Civil, ya no es tal en nuestros días. Actualmente, cuando los legitimarios heredan, ya han alcanzado una edad madura, una estabilidad económica y profesional, no necesitan la protección de la ley, pueden no tener interés en heredar y están dispuestos a ceder sus derechos a herederos más desvalidos, por lo que sería preferible permitirle al testador que disponga de sus bienes de la forma en que mejor le parezca, principalmente a favor de su cónyuge o pareja. Si el legitimario tiene cubiertas sus necesidades vitales, no se vislumbra la razón de que la ley opere por sobre una voluntad expresa del causante, en un sentido contrario. Se fuerza a disponer de la última voluntad del causante, a favor de quienes ni siquiera, en muchos casos, lo necesitan. Con razón, Walker se pregunta "por qué constreñir al causante a efectuar reparticiones que no necesariamente desea hacer -porque, de permitírselo, es probable que haría otras-, limitando la autonomía de su voluntad en base a supuestos hoy en día inexistentes" 35 .

Las asignaciones forzosas deben ser eliminadas y buscar otro mecanismo, con carácter alimenticio, para los casos en que efectivamente algún miembro de la familia esté en un estado de necesidad (hijos menores, discapacitados, etcétera), y no hay que temer a un sistema de amplia libertad de testar como el que ya rige, en general, en Inglaterra, Canadá, en la mayor parte de Estados Unidos de América, México, Costa Rica y Nicaragua.

Veamos ahora las razones particulares para aceptar los pactos de institución y renuncia.

En primer lugar, admitir los pactos de institución en nuestra legislación, daría mayor margen a la autonomía de la voluntad, en materia sucesoria, cuestión que se viene observando hace ya un tiempo, en otras ramas o disciplinas jurídicas, incluso en Derecho de Familia, tradicionalmente reticente a dar espacio a la autonomía de la voluntad. Piénsese por ejemplo, como en materia de familia, todas las últimas reformas

33 El desarrollo de cada argumentación puede verse en ElORRIAGA, 2019, pp. 88-95. Similares argumentos en WALKER, 2019, pp. 565-583.

34 Así, Ragel, 2014, p. 23.

35 WALKER, 2019, p. 570. 
así lo ponen de manifiesto, verbi gracia, los acuerdos ahora permitidos, en lo relativo al cuidado de los hijos, a la patria potestad, a la compensación económica, etcétera ${ }^{36}$.

Los pactos de institución no son, por lo demás, sino un ejercicio de la facultad de disposición del dominio del futuro causante sobre sus bienes. La Constitución Política (art. $19 \mathrm{~N}^{\circ} 24$, inc. $3^{\circ}$ ) asegura a todas las personas que: nadie puede, en caso alguno, ser privado de su propiedad, del bien sobre que recae o de alguno de los atributos o facultades esenciales del dominio... y una de las facultades esenciales del dominio es precisamente, la de disposición ${ }^{37}$. Queremos destacar, en lo que interesa para este trabajo, que la facultad de disposición no solo se limita a la facultad de poder enajenar o gravar libremente los bienes, sino que también comprende la libertad o elección de la persona con quien se va a contratar o quien será el destinatario de esos bienes, según sean actos gratuitos u onerosos. También, en el plano constitucional, la única obligación directa que el constituyente impone a los padres, es el deber de educar a sus hijos (art. 19 No 10). Cumplida tal cosa, los padres debieran tener absoluta libertad para disponer de sus bienes, por ejemplo, mediante estos pactos, salvo el estado de necesidad de alguno de ellos.

Otro argumento para aceptar los pactos de institución, es que ello evitaría o disminuiría la celebración de actos encubiertos o fraudulentos. Como observan Domínguez Benavente y Domínguez Águila, serviría para poner el derecho de acuerdo con la realidad, desde que habrá de reconocerse que las personas, dueñas de alguna fortuna más o menos importante, recurren a diversos subterfugios para regular en vida, la suerte de sus bienes después de muertos. Por otra parte, son comunes contratos de seguros de vida, depósitos en cuentas previsionales y otros que permiten eludir la prohibición general de los pactos sucesorios $^{38}$. La admisibilidad clara y explícita de los pactos de institución, evitaría la existencia de contratos simulados que celebrándose con la apariencia de contratos inter vivos, persiguen, en realidad, efectos mortis causa ${ }^{39}$.

También, en defensa de estos pactos, hay una razón más práctica que radica en la riqueza que al sistema de sucesión proporciona la inclusión de una nueva figura: los particulares tendrán así, la posibilidad de ordenar el fin de sus bienes mediante más

36 Vid. al respecto BARCia, 2009, pp. 107-127; Lepín, 2013, pp. 93-103; Moreno, 2007, pp. 133149; SCHMIDT, 1999, pp. 105-119; SAAVEDRA, 2007, pp. 113-132.

${ }^{37} \mathrm{La}$ arista constitucional de nuestro tema excede a este trabajo por lo que sugerimos ver RAJEVIC, 1996, pp. 23-97.

38 Vid. por todos Domínguez Benavente y Domínguez Águila, 2011, p. 41.

39 Así, la Corte de Apelaciones de Temuco declaró la nulidad absoluta, por simulación de dos contratos de compraventa entre los padres y uno de sus hijos, afirmando que en dichos contratos la compradora no pagó el precio y que son ficticios los que se determinan en ellos, por lo que dichas convenciones carecen de ese requisito esencial. De acuerdo con la sentencia, en los contratos no solo se falseó su naturaleza sino que, en verdad, entre las partes no hubo consentimiento real y efectivo, al pactar las prestaciones que recíprocamente se imponen, ni hubo entre ellas motivo determinante de las convenciones sino que simularon compraventas, con el fin de soslayar la prohibición del inciso $1^{\circ}$ del artículo 1463 del Código Civil, puesto que en realidad esos contratos constituyen donaciones que permitieron a los causantes transferir la totalidad de sus bienes raíces, en beneficio exclusivo de uno de sus hijos. Corte de Apelaciones de Temuco, 16.8.2004, rol 11862002, confirmada por la Corte Suprema, 25.1.2007, rol 4265-2004. En igual sentido, Corte de Apelaciones de Punta Arenas, 26.1.2007, rol 361-2006, confirmada por la Corte Suprema, 2.7.2008, rol 1652-2007. 
cauces, incluyendo el testamento, las donaciones y los pactos o contratos sucesorios (en especial, los de institución), utilizando la figura que más se ajuste a sus necesidades ${ }^{40}$. La inclusión de estos pactos, como una nueva forma de testar, supone, a pesar de una restricción de la autonomía del testador, una ampliación de la libertad de testar formal, al dar al causante todas las formas posibles para ordenar su sucesión ${ }^{41}$. Así, los pactos de institución ofertan otra jurídica más para fines dignos de tutela (como puede ser la conservación de la unidad de patrimonio o fincas, empresas o industrias) que no pueden lograse mediante las formas jurídicas existentes en el actual sistema del Código Civil como son las donaciones o testamento ${ }^{42}$.

Pero, el argumento decisivo para nosotros, que inclina la balanza en favor de la aceptación de los pactos de institución, está basado en las máximas de la experiencia: es el causante y no la ley a priori, quien está en mejor posición para hacer una mejor distribución de sus bienes. Solo él conoce la dinámica y vicisitudes familiares que lo llevan a disponer de una u otra manera de su patrimonio, sin estar atado a reglas prefijas y abstractas; él más que nadie sabe quién es merecedor de su gratitud, quiénes están necesitados, etcétera. Tal conocimiento lo ha obtenido de años de vida familiar que ninguna ley puede sustituir. Por eso, compartimos plenamente las palabras de un autor español cuando afirma que el Derecho de sucesiones debiera fundarse "más en los sentimientos que en la sangre" 43 . La sucesión intestada, por tanto, debe operar como última opción, es decir, aplicarse en defecto o a falta de testamento o pactos sucesorios.

En cuanto a los pactos de no suceder o de renuncia a los derechos eventuales en una herencia futura, han de aceptarse porque solo miran al interés individual del renunciante, en este caso, el del futuro heredero que abdica. La renuncia a la herencia es una suerte de liberalidad que no debiera merecer cuestionamiento alguno, ya que solo afecta al renunciante y beneficia, eventualmente, a otros futuros herederos. Así, por ejemplo, qué de objetable tiene que personas mayores o viudos renuncien a la herencia de su cónyuge en favor de los hijos, los nietos o los sobrinos porque lo necesitan más o lo pueden disfrutar durante más tiempo. Motivos muy diversos y a veces simplemente personales pueden conducir a la renuncia, la que si solo afecta al renunciante debiera encontrar un camino despejado para su materialización.

Asimismo, no vemos una razón sustantiva o material que justifique poder renunciar a la herencia solo una vez abierta la sucesión (repudiación ${ }^{44}$ ), pero no antes. La voluntad del renunciante en uno y otro caso, es igual, no llevar parte en la herencia. En ambas hipótesis, hay una dejación o abandono voluntario del derecho a suceder, ello es lo relevante.

\footnotetext{
40 CÁmara, 2011, pp. 293-294.

41 Roca Sastre, 1948 , p. 400.

42 CÁMARA, 2013, p. 385.

43 Ragel, 2014, p. 23.

${ }^{44}$ Véase el concepto, naturaleza y modalidades de la renuncia en materia sucesoria en PlanAs, 2017,
} pp. 33-47; Rogel, 2011, pp. 43-82. 
Además, estos pactos de renuncia o abdicativos resultan útiles porque amplían la capacidad de disposición del futuro causante y le permiten asignar con preferencia sus bienes a hijos incapacitados, menores o en situación económica desfavorable o a su cónyuge.

Una razón no menor, agreguemos, es que si se permiten estas renuncias, los otros herederos tendrán más incentivos a aceptar la herencia porque obviamente el as hereditario se repartirá entre menos. Siempre será mejor, por razones de certeza y tráfico jurídicos y del crédito que los herederos acepten las herencias, antes que las repudien.

En resumen, la prohibición general de pactos sucesorios del artículo 1463 solo debiese quedar restringida a los pactos de disposición y dejar fuera de tal prohibición a los de institución y renuncia. La implicancia moral o derechamente la inmoralidad y la especulación con la vida del causante, que conllevan el disponer de una herencia futura mientras aquel vive, hacen aconsejable mantener la proscripción de los pactos de disposición.

\section{Conclusiones}

Las razones que tradicionalmente se han dado para prohibir los pactos de sucesión futura, esto es, inmorales y atentar contra la libertad de testar y la igualdad de los hijos, no son convincentes (en la renta vitalicia, los seguros de vida, el seguro de desgravamen, el usufructo vitalicio, también la muerte de un sujeto es consideración relevante) y el contexto histórico y la realidad de la familia de entonces que justificaban la prohibición, ya no existen.

Los pactos de institución deben ser aceptados, entre otras razones, porque son una manifestación de la facultad de disposición del dominio, garantizada constitucionalmente; dan mayor cabida a la autonomía de la voluntad en materia sucesoria, tendencia que incluso se observa en Derecho de Familia; evitarían o disminuirían la celebración de actos encubiertos o fraudulentos celebrados en vida para regular la suerte de los bienes del futuro causante; suman otra posibilidad, además de la ley y el testamento, de ordenar el fin de los bienes del mismo y el causante está en mejor posición, para hacer la mejor distribución de sus bienes que una hecha ex ante por la ley.

En cuanto a los pactos de no suceder o de renuncia, abogamos por su aceptación porque solo miran al interés individual del renunciante; no hay una razón sustantiva para poder renunciar a la herencia solo una vez abierta la sucesión pero no antes, pues en ambos casos, hay una dejación o abandono voluntario del derecho a suceder; estos pactos de renuncia resultan útiles porque amplían la capacidad de disposición del futuro causante y le permiten asignar con preferencia sus bienes a herederos necesitados; finalmente, si se permiten estas renuncias, los otros herederos tendrán más incentivos a aceptar la herencia, lo que siempre es más conveniente que la repudiación para la certeza y tráfico jurídicos y el crédito.

En síntesis, los pactos de institución y de renuncia deben ser aceptados en nuestro ordenamiento jurídico, quedando reservada la prohibición general del artículo 1463 , solo a los pactos de disposición por la implicancia moral que conllevan. 


\section{BIBLIOGRAFÍA}

Abeliuk Manasevich, René, 2009: "Evolución de la legislación civil chilena en materia de Derecho de Familia y Sucesorio", en Enrique Alcalde y Hugo Fábrega (coordinadores), Estudios Jurídicos en homenaje al profesor Pablo Rodríguez Grez, Santiago, Ediciones Universidad del Desarrollo, pp. 55-70.

Barcia Lehmann, Rodrigo, 2009: "La autonomía privada en el Derecho de Familia", Revista de Derecho (Universidad Finis Terrae), No 13, pp. 107-127.

Barría Paredes, Manuel, 2015: Asignaciones forzosas y libertad de testar, Santiago, Thomson Reuters. Barría Paredes, Manuel, 2018: "La intangibilidad cuantitativa de la legítima en el Código Civil chileno. Una mirada desde el Derecho Sudamericano", Revista de Derecho Privado (Universidad Externado de Colombia), $\mathrm{N}^{\circ} 35$, pp. 129-161.

Bello, Andrés, 1888: Obras completas, Tomo XII (Proyecto de Código Civil, 1853), Santiago, impreso por Pedro Ramírez.

CÁmara Lapuente, Sergio, 2011: "Freedom of testation, legal inheritance rights and public order under Spanish Law”, en E. Arroyo i Amayuelas y M. Anderson (eds.), The Law of Succession: Testamentary Freedom. European Perspectives, Groningen, Europa Law Publishers, pp. 269-305.

Cámara Lapuente, Sergio, 2013: "La sucesión intestada. La sucesión contractual”, en Miguel Ángel Pérez Álvarez et al. (autores), Curso de Derecho Civil (V). Derecho de Sucesiones, Madrid, Colex, pp. 381-390.

CASTÁn VÁsQuez, José María, 1964: "Sucesión forzosa y sucesión contractual”, Revista de Derecho (Universidad de Concepción), No 127 , pp. 3-102.

Claro Solar, Luis, 1992: Explicaciones de Derecho Civil Chileno y Comparado, Santiago, Editorial Jurídica de Chile.

Córdoba, Marcos M., 2019: "La recepción de la nueva norma por la doctrina. Artículo 1010. Herencia futura”, en Ricardo Luis Lorenzetti (director), Código Civil y Comercial de la Nación. Comentado, Tomo XII-B, Buenos Aires, Rubinzal-Culzoni Editores, pp. 92-115.

Díez-Picazo, Luis y Gullón, Antonio, 2000: Sistema de Derecho Civil, vol. IV, Madrid, Tecnos.

Domínguez ÁGuila, Ramón, 2012: Teoría general del negocio jurídico, Santiago, Editorial Jurídica de Chile.

Domínguez Benavente, Ramón y Domínguez Águila, Ramón, 2011: Derecho Sucesorio, Tomo I, Santiago, Editorial Jurídica de Chile.

Doyharcabal Casse, Solange, 2008: "Pactos sobre sucesión futura o sucesión contractual en la legislación francesa y española aragonesa”, Revista de Derecho y Ciencias Penales (Universidad San Sebastián), N 10, pp. 23-34.

Elorriaga de Bonis, Fabián, 2010: Derecho Sucesorio, Santiago, LexisNexis.

Elorriaga DE Bonis, Fabián, 2019: "La libertad de testar y sus restricciones. Consideraciones para su eventual revisión en Chile”, en Manuel Barría Paredes et al. (directores y coordinadores), Estudios de Derecho Privado en homenaje al profesor Daniel Peñailillo Arévalo, Santiago, Thomson Reuters, pp. 67-102.

Ferrer, Francisco A. M., 2015: “Aspectos de las sucesiones en el nuevo Código”, Revista Jurídica La Ley (Buenos Aires), vol. 2015-E.

Fornieles, Salvador, 1941: Tratado de Sucesiones, Tomo I, Buenos Aires, Librería Jurídica.

Grimaldi, Michel, 2015: "La libertad testamentaria”, en Manuel Barría et al. (editores), Estudios de Derecho Privado. Homenaje al profesor Ramón Domínguez Águila, Santiago, Thomson Reuters, pp. 191-215.

Guzmán Brito, Alejandro, 2001: Derecho Privado Romano, Tomo II, Santiago, Editorial Jurídica de Chile.

León Hurtado, Avelino, 1983: El objeto en los actos jurídicos, Santiago, Editorial Jurídica de Chile. 
Lepín Molina, Cristián, 2013: "Autonomía de la voluntad y los acuerdos conyugales”, en Carmen Domínguez, Joel González, Marcelo Barrientos, Juan Luis Goldenberg (coordinadores), Estudios de Derecho Civil VIII, Santiago, LegalPublishing, pp. 93-103.

Martinic Galetovic, María Dora, 2005: "Las asignaciones forzosas y la libertad de testar en el Código de Bello”, en María Dora Martinic y Muricio Tapia (coordinadores), Sesquicentenario del Código Civil de Andrés Bello, Tomo I, Santiago, LexisNexis, pp. 479-486.

Messineo, Francisco, 1979: Derecho Civil y Comercial, Tomo VIII, Buenos Aires, Ediciones Jurídicas Europa-América.

Moreno Concha, Ximena, 2007: "Paulatina incorporación de la autonomía de la voluntad en el Derecho matrimonial chileno”, en Hernán Corral y María Sara Rodríguez (coordinadores), Estudios de Derecho Civil II, Santiago, LegalPublishing, pp. 133-149.

NAVAs NAVArRo, Susana, 2011: "Libertad de testar versus libertad de celebrar pactos sucesorios y costes de transacción. Aproximaciones desde el derecho de sucesiones catalán”, Anuario de Derecho Civil, t. LXIV, fasc. I, pp. 41-74.

Peñailillo Arévalo, Daniel, 1968: "El principio de la igualdad en el Derecho sucesorio", Revista de Derecho (Universidad de Concepción), No 143, pp. 59-109.

Planas Ballvé, María, 2017: Los pactos de renuncia al derecho a la legítima futura. Tesis para optar al grado de doctor, Universidad Autónoma de Barcelona.

Ragel SÁnChez, Luis Felipe, 2014: La cautela gualdense o socini y el artículo 820.3 del Código Civil, Madrid, Dykinson.

Rajevic, Enrique, 1996: "Limitaciones, reserva legal y contenido esencial de la propiedad privada", Revista Chilena de Derecho (Pontificia Universidad Católica de Chile), vol. 23, No 1, pp. 23-97.

Ripert, Georges y Boulanger, Jean, 1965: Tratado de Derecho Civil, Tomo X, vol. I, Buenos Aires, La Ley.

Roca Sastre, Ramón María, 1948: "La sucesión contractual en Derecho común y en las legislaciones forales”, en Estudios de Derecho Privado, t. II, Madrid, edit. Revista de Derecho Privado, pp. 341-423.

Rodríguez Grez, Pablo, 1989: "El régimen patrimonial del matrimonio y el derecho sucesorio”, Revista de Derecho (Universidad Central), pp. 25-34.

Rodríguez Grez, Pablo, 2006: Instituciones de Derecho Sucesorio, Santiago, Editorial Jurídica de Chile.

Rodríguez Pinto, María Sara, 2010: "Contracción de las asignaciones forzosas. Una reforma urgente al sistema sucesorio chileno”, en Departamento de Derecho Privado Universidad de Concepción (coord.), Estudios de Derecho Civil V, Santiago, LegalPublishing, pp. 423-433.

Rodríguez-Uría SuÁrez, Isabel, 2013: La ley aplicable a los pactos sucesorios. Tesis para optar al grado de doctor, Universidad de Santiago de Compostela.

Rogel Vide, Carlos, 2011: Renuncia y repudiación de la berencia en el Código Civil, Madrid, Reus.

SaAvedra Alvarado, Ricardo, 2007: "Autonomía de la voluntad y protección de la familia frente a la actual realidad sucesoria: la búsqueda de nuevos equilibrios entre dos principios fundamentales”, en Hernán Corral y María Sara Rodríguez (coordinadores), Estudios de Derecho Civil II, Santiago, LegalPublishing, pp. 113-132.

Schmidt Hотт, Claudia, 1999: "Régimen patrimonial y autonomía de la voluntad", Revista Chilena de Derecho, vol. 26, Nº 1, pp. 105-119.

Somarriva Undurraga, Manuel, 2005: Derecho Sucesorio, Tomo I, Santiago, Editorial Jurídica de Chile.

WaLKer SILVA, Nathalie, 2019: "El anacronismo de las asignaciones forzosas y el necesario reconocimiento a la libertad para testar en Chile”, en Esteban Pereira (editor), Fundamentos filosóficos del Derecho Civil chileno, Santiago, Rubicón, pp. 565-583. 


\section{Jurisprudencia citada}

Conte Suprema, sentencia de fecha 31 de mayo de 1907, Revista de Derecho y Jurisprudencia, tomo 7 , sec. $1^{\text {a }}$, p. 5.

Corte Suprema, sentencia de fecha 20 de agosto de 1928, Revista de Derecho y Jurisprudencia, tomo 26 , sec. $1^{\text {a }}$, p. 484.

Corte de Apelaciones de Valparaíso, sentencia de fecha 29 de abril de 1933, Revista de Derecho y Jurisprudencia, tomo 31 , sec. $1^{\text {a }}$, p. 337.

Corte Suprema, sentencia de fecha 26 de abril de 1934, Revista de Derecho y Jurisprudencia, tomo 31 , sec. $1^{\text {a }}$, p. 337.

Conte Suprema, sentencia de fecha 5 de enero de 1954, Revista de Derecho y Jurisprudencia, tomo 51 , sec. $1^{\text {a }}$, p. 17.

Corte de Apelaciones de Santiago, sentencia de fecha 29 de noviembre de 1960, Revista de Derecho y Jurisprudencia, tomo 57 , sec. $2^{\text {a }}$, p. 97.

Corte de Apelaciones de Temuco, sentencia de fecha 16 de agosto de 2004, rol 1186-2002.

CorTe Suprema, sentencia de fecha 25 de enero de 2007, rol 4265-2004.

Corte de Apelaciones de Punta Arenas, sentencia de fecha 26 de enero de 2007, rol 361-2006.

CoRte Suprema, sentencia de fecha 2 de julio de 2008, rol 1652-2007. 